\title{
Contribution of Advanced Demand Side Management to Angular Stability of Interconnected Transmission Networks
}

DOI:

10.1109/ISGTEurope.2019.8905681

\section{Document Version}

Final published version

Link to publication record in Manchester Research Explorer

\section{Citation for published version (APA):}

Wang, M., \& Milanovic, J. V. (2019). Contribution of Advanced Demand Side Management to Angular Stability of Interconnected Transmission Networks. In 2019 IEEE PES Innovative Smart Grid Technologies Conference Europe (ISGT-Europe) IEEE. https://doi.org/10.1109/ISGTEurope.2019.8905681

\section{Published in:}

2019 IEEE PES Innovative Smart Grid Technologies Conference Europe (ISGT-Europe)

\section{Citing this paper}

Please note that where the full-text provided on Manchester Research Explorer is the Author Accepted Manuscript or Proof version this may differ from the final Published version. If citing, it is advised that you check and use the publisher's definitive version.

\section{General rights}

Copyright and moral rights for the publications made accessible in the Research Explorer are retained by the authors and/or other copyright owners and it is a condition of accessing publications that users recognise and abide by the legal requirements associated with these rights.

\section{Takedown policy}

If you believe that this document breaches copyright please refer to the University of Manchester's Takedown Procedures [http://man.ac.uk/04Y6Bo] or contact uml.scholarlycommunications@manchester.ac.uk providing relevant details, so we can investigate your claim.

\section{OPEN ACCESS}




\title{
Contribution of Advanced Demand Side Management to Angular Stability of Interconnected Transmission Networks
}

\author{
Mengxuan Wang, Student member, IEEE and Jovica V. Milanovic, Fellow, IEEE \\ School of Electrical and Electronic Engineering \\ The University of Manchester \\ Manchester, United Kingdom \\ mengxuan.wang@postgrad.manchester.ac.uk, milanovic@manchester.ac.uk
}

\begin{abstract}
The implementation of Demand Side Management (DSM) in order to enhance power system operational flexibility has gained more and more attention during the past decade. However, DSM could endanger the system stability because it changes the characteristics of system demands. This paper establishes the overall impacts of DSM on angular stability of power system with high penetration of Renewable Energy Sources (RES) and high system operational uncertainty. The overall effects of DSM are assessed by considering the distance (in terms of Euclidean Norm) between stability manifolds of the system before and after applying DSM. The results show that changes of Euclidean Norm with pre-defined positive direction can be adopted to indicate the overall effect of DSM on system angular stability. They further indicate that depending on the system inertia, RES penetration levels and DSM application levels, the effects of DSM on power system angular stability could be very different. A modified version of the 68-bus NETSNYPS test system in DigSilent/PowerFactory environment has been adopted to perform dynamic simulations.
\end{abstract}

Index Terms - Angular stability, demand side management, Euclidean Norm, probabilistic analysis, renewable energy resources.

\section{INTRODUCTION}

With the ever growing connection of stochastically varying renewable energy sources (RES) and new types of temporally and spatially varying loads, power system dynamic performance is changing and past operational experiences may not be as valuable as they used to be to ensure stable operation of the system. The recognition of the need for additional support by other participants in electricity supply chain led to more attention being paid to the demand side management (DSM) and the potential of using DSM to provide operational flexibility and stability support to the system. DSM can be defined as the optimisation of energy use of system customers through different methods, including financial incentives or raising awareness of environmental sustainability. With the aim to study the impacts of DSM on power system voltage stability, an under speed load shedding (USLS) scheme has been applied in [1]. In [2], it has been proved that DSM can improve steady-state voltage stability margins by adopting an algorithm of iterative linear programming. In terms of power system frequency stability, a frequency based decentralized DSM control scheme and an autonomous DSM control method are introduced in [3] and [4], respectively. Moreover, DSM can provide frequency stability support in the case of disturbances [5]. However, to the best of the authors' knowledge, there are no published research or application results in open literature demonstrating the impacts of DSM on power system angular stability.

A Monte Carlo based probabilistic framework is implemented in this paper for assessing and quantifying the overall effect of DSM on the angular stability (small and large disturbance) of power systems for different RES penetration levels and different system inertia. The operational uncertainties produced by the variations of RES generation, loading levels and system faults (position and duration of fault) have all been considered. A modified version of the IEEE 68bus NETS-NYPS test system with corresponding loading scenarios developed in previous studies, is adopted to carry out all dynamic simulations in DigSilent/PowerFactory.

\section{CONTRIBUTION OF DSM TO SYSTEM ANGULAR STABILITY}

\section{A. DSM and Power System Stability}

Due to the fact that DSM changes size of system load demand, which subsequently changes spare capacity of synchronous machines, system dynamic responses can be highly affected by DSM actions. It has been recognised in [6] that system angular stability is highly affected by system loading in such a way that high system loading can result in system angular instability. To be more specific, better angular stability performance is expected from system with higher spare capacity of synchronous machines while reduced spare capacity or disconnection of synchronous machines may result in detrimental effect on system angular stability [7]. 
The application of DSM is expected to increase generators' spare capacity during peak-hours and subsequently, improve system angular stability performance. However, reconnection of disconnected loads is expected to reduce the ability of synchronous machines to support system stability and therefore, resulting in decreased system angular stability. Moreover, system inertia is another essential factor that determines the system angular stability performance in such a way that systems with higher inertia present better angular stability performance [7].

\section{B. Power System Angular Stability}

As defined in [8] and elsewhere, power system angular stability refers to the ability of synchronous machines of an interconnected power system to remain in synchronism after being subjected to small or large disturbance.

In this study, system angular stability performance is quantified through corresponding stability indices: the damping of the most critical electromechanical mode (1) for small-disturbance stability and the transient stability index (TSI) (2) for large disturbance (transient) stability.

$$
\begin{gathered}
\lambda=\sigma+j \omega \\
\text { TSI }=100 \times \frac{360-\delta_{\max }}{360+\delta_{\max }}
\end{gathered}
$$

In (1), $\lambda$ represents the eigenvalue of the most critical electromechanical mode and $\sigma$ represents the damping of the same mode. In (2), $\delta_{\max }$ represents the maximum angle deviation between any two generators within the study period. The system angular stability is quantified by the above mentioned indices in such a way that larger damping $(\sigma)$ values (most critical electromechanical mode) and larger TSI values indicate better system angular stability performance.

\section{NETWORK MODELLING}

\section{A. System Under Study}

As mentioned above, a modified version of the IEEE 68bus NETS-NYPS system, as shown in Fig.1, is adopted. It contains five inter-connected areas, ten renewable integration points (one wind unit and one PV unit at each point) and thirty-five constant impedance loads.

All loads in Fig.1 have been divided into two categories based on their load sizes, namely large industrial customers (loads with small demand values) and distribution networks (DNs) (loads with large demand values). Twelve loads (five in NETS, five in NYPS and two in other areas) are modelled as large industrial connections; all other loads are modelled as integration of distribution networks (DNs). In order to represent system dynamic performances for different power generations and load demands, normalised daily RES profile $[9,10]$ and normalised daily loading curves [11] have been added to the test network.

\section{B. System Uncertainties}

System operational uncertainties associated with the RES generation, load demands and system disturbances are considered and modelled. The wind speed and PV output are assumed to follow Weibull distribution [12] and Beta distribution [13], respectively. Furthermore, the load demands

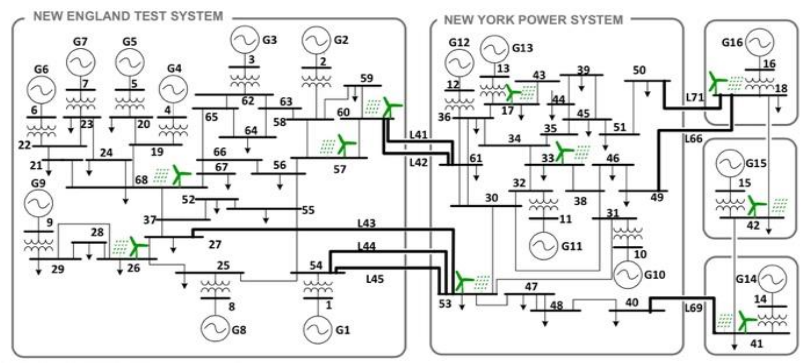

Figure 1. Test network (modified 68 bus NETS-NYPS system).

follow a normal distribution [14]. In order to apply these uncertainties, real power consumption or generation values from daily loading or RES generation profiles are multiplied with scaling factors generated by load demand and RES uncertainties. Finally, faulted lines and fault positions along the line are selected randomly while the fault duration is assumed to follow a normal distribution [15].

\section{THE METHDOLOGY}

\section{A. Probabilistic Analysis Method}

All daily profiles (system loading and RES generation) have been segmented into 24 hourly values and a Monte Carlo based probabilistic simulation is performed for each hour. Two separate Monte Carlo simulations are conducted in DigSILENT PowerFactory, one for small-disturbance stability study and one for large-disturbance stability study at each test hour while the relevant and common for both types of study, system uncertainties, are generated by Matlab.

At each test hour, system uncertainties are generated and exported as files, which are prepared for further Monte Carlo simulations. All uncertainty inputs are following their corresponding probability distributions. Matlab also calculates power outputs of synchronous machines based on optimal power flow (OPF) by using Matpower [16]. Because of the application of the probabilistic analysis method, Monte Carlo simulations produce a huge set of stability indices for both small-disturbance and transient studies at each hour. The mean values of corresponding stability indices have been adopted to illustrate the angular stability performance and to generate 3-dimensional surface plots.

\section{B. DSM Application Methods}

The DSM adopted in this study is load shifting, the system loading is decreased at peak hours and increased at off-peak hours. It has been assumed that the amount of load reduction (in MW) is equal to the load increase (in MW).

Four loads (L17, 18, 41 and 42) are selected to implement DSM as they are the four most critical loads in the test system [17]. The DSM has been assumed to be applied (reduction or increase of demand) at 11 hours throughout the day (24 hours). The DSM application hours and corresponding DSM capacities are summarised in Table I, where the load increase has been marked with upward arrows and the load reduction has been marked with downward arrows. At each hour, all DSM applied loads share the same DSM capacity and it is calculated based on (3).

$$
\text { DSM Capacity }(\%)=\frac{\text { Power Change of L17,18,41,42 at hour i }}{\text { Total Power of L17,18,41,42 at hour i }} \times 100 \%
$$




\section{Euclidean Norm}

System angular stability performance is represented by composite 3-dimensional manifolds in this study that combine transient and small disturbance system performance. An appropriate measure or index is therefore needed to access and quantify the overall impacts of DSM on system angular stability, i.e., relative location of manifolds with and without DSM. The Euclidean Norm has been adopted in this study to achieve above-mentioned objective, i.e., to measure the distance between the two composite stability manifolds.

Euclidean Norm is a common measure of distance in multi-dimensional space [18]. The Euclidean Norm is calculated by (4). The percentage change of Euclidean Norm is calculated based on (5).

$$
\begin{gathered}
L_{a b}=\left(\sum_{k=1}^{n}\left(x_{a k}-x_{b k}\right)^{2}\right)^{1 / 2} \\
\text { Change }(\%)=\frac{\text { Result Without DSM-Result With DSM }}{\text { Result Without DSM }} \times 100 \%
\end{gathered}
$$

Where $\mathrm{a}$ and $\mathrm{b}$ represents two objectives in an $\mathrm{n}$ dimensional space and $x_{a k}$ and $x_{b k}$ are the $k$ th variable values of individuals $a$ and $b$, respectively [18]. In the case of this study, $a$ and $b$ are two surface plots representing system angular stability performance under different system conditions and $\mathrm{n}$ equals to three. $x_{a k}$ and $x_{b k}$ are different damping values, time values and TSI values extracted from different surface plots.

\section{Study Cases}

In this study, five study cases with different RES penetration levels, loading levels and system inertia levels have been developed. All study cases are listed in Table II.

Case 1 has been selected as the base case that provides a reference for further system angular stability studies. In Cases 2 and 3, it has been assumed that increases of RES penetration levels and decreases of loading levels will not lead to reductions in system inertia. On the other hand, in Cases 4 and 5 , the system inertia is reduced as a consequence of increased RES penetration levels and decreased loading levels. System loading level is adjusted by curtailing system demand at all controlled buses simultaneously.

\section{RESULTS AND ANALYSIS}

\section{A. Impacts of DSM on System Angular Stability}

In this study, 3-dimensional surface plots are adopted to visualize the overall system angular stability performance. All 3-dimensional surface plots are produced based on mean values of damping (the most critical electromechanical mode) and mean values of TSI. Mean values of TSI, time and mean values of damping have been adopted as $\mathrm{x}$-axis, $\mathrm{y}$-axis and $\mathrm{z}$ axis, respectively.

Plots of cases 2 to 5 contain three individual surfaces: the surface of system angular stability performance without DSM (white surface), the surface of system angular stability performance with DSM (black surface) and the reference surface (grey surface). The surface of system angular stability performance without DSM in Case 1 has been adopted as the reference surface. The 3-dimensional surface plots of Cases 2 to 5 are shown as Fig. 2 to Fig. 5, respectively.
TABLE I

DSM APPLICATION HOURS AND CORRESPODING DSM CAPACITIES (\%)

\begin{tabular}{|c|c|c|c|}
\hline Hour & DSM Capacity & Hour & DSM Capacity \\
\hline $1: 00$ & $11.7 \% \uparrow$ & $16: 00$ & $12.5 \% \downarrow$ \\
\hline $2: 00$ & $12.1 \% \uparrow$ & $17: 00$ & $16.6 \% \downarrow$ \\
\hline $3: 00$ & $12.7 \% \uparrow$ & $18: 00$ & $9.4 \% \downarrow$ \\
\hline $4: 00$ & $36.3 \% \uparrow$ & $19: 00$ & $6.7 \% \downarrow$ \\
\hline $5: 00$ & $3.0 \% \uparrow$ & $24: 00$ & $12.8 \% \uparrow$ \\
\hline $11: 00$ & $6.0 \% \downarrow$ & & \\
\hline
\end{tabular}

TABLE II

STUDY CASES

\begin{tabular}{|c|c|c|c|}
\hline $\begin{array}{c}\text { Case } \\
\text { Name }\end{array}$ & $\begin{array}{c}\text { RES Penetration } \\
\text { Level }\end{array}$ & Loading Level & System Inertia \\
\hline Case 1 & $0 \%$ & $100 \%$ & Fixed \\
\hline Case 2 & $50 \%$ & $100 \%$ & Fixed \\
\hline Case 3 & $50 \%$ & $60 \%$ & Fixed \\
\hline Case 4 & $30 \%$ & $100 \%$ & Reduced \\
\hline Case 5 & $60 \%$ & $60 \%$ & Reduced \\
\hline
\end{tabular}

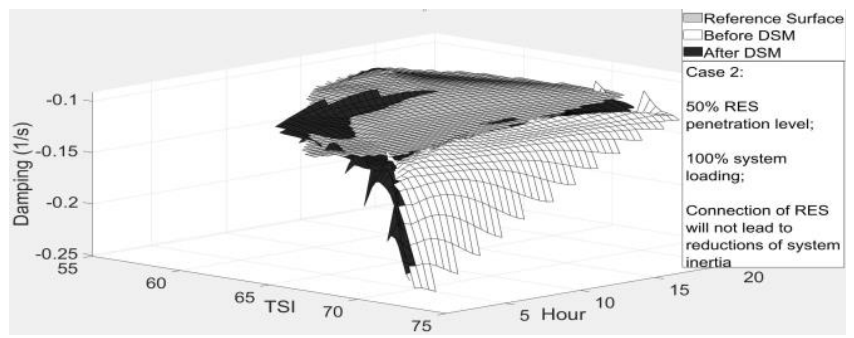

Figure 2. 3-D surface plot of Case 2 (50\% RES, $100 \%$ loading, fixed inertia).

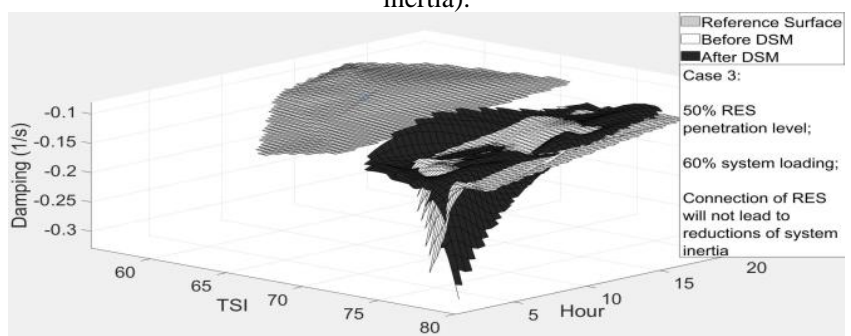

Figure 3. 3-D surface plot of Case 3 (50\% RES, 60\% loading, fixed inertia).

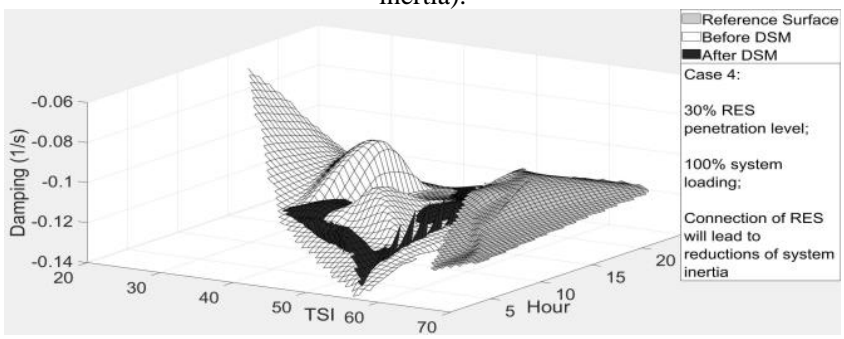

Figure 4. 3-D surface plot of Case 4 (30\% RES, 100\% loading, reduced inertia).

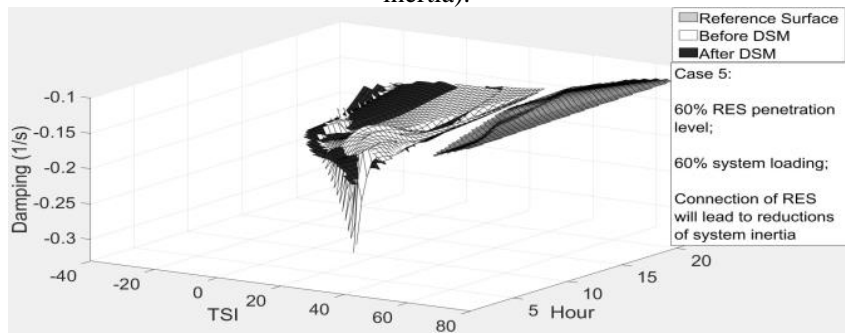

Figure 5. 3-D surface plot of Case 5 (60\% RES, $60 \%$ loading, reduced inertia). 
In Fig. 2 to Fig. 5, it can be seen that all the white surfaces have moved away from the grey surface (reference surface) as a result of changes in RES penetration level, system loading level and system inertia. When the integration of RES and system de-loading does not lead to system inertia reductions (Fig. 2 and Fig. 3), the white surface moves towards larger absolute values of damping and larger TSI values, therefore, integration of RES and system de-loading improves the overall system angular stability. On the other hand, when the system inertia is reduced because of RES penetration and system de-loading, (Fig. 4 and Fig. 5), the white surface moves in the direction of smaller absolute values of damping and TSI, which indicate integration of RES and system deloading leads to worse system angular stability.

In Case 2 (Fig. 2), after applying DSM, the black surface is closer to the reference surface than the white surface, although more overlaps have appeared due to the load increases at hours 1 to 5. In Case 3 (Fig. 3), similar to Case 2, the black surface is slightly closer to the reference surface, but there are no overlaps between them. DSM therefore can "shift" the white surface to be closer to the reference one, i.e., "restore" system performance to previous levels, but its effects are limited.

Regarding Case 4 (Fig. 4), as a consequence of reduced system inertia, magnitudes of both damping mean values and TSI mean values have decreased significantly, the variation ranges of these two indices have increased a lot. By comparing the white surface and the black surface, it can be noticed that a flatter surface can been obtained by applying DSM, both the damping variation range and the TSI variation range have been reduced. The shift of the white surface (system performance with RES and without DSM) towards the reference surface is very small, and there is still a large distance between the black surface (system performance with RES and with DSM) and the reference surface.

Finally, in terms of Case 5 (Fig. 5), the white surface is further away from the reference surface and, because of the very low system inertia, a very large index variation range can be found in system angular stability performances. When the DSM is applied, the black surface is below the white surface most of the time, which indicates that DSM can result in better small-disturbance stability performance most of the time. However, TSI mean values are decreased most of the time due to the application of DSM and more unstable cases have been obtained from simulations. Therefore, DSM leads to even worse system angular stability performance than prior to applying the DSM.

\section{B. Quantifying the Distance Between System Manifolds}

For the purposes of quantifying the movements of surfaces and the impacts of DSM in a 3-dimensional space, the Euclidean Norm (4) is adopted in this study. Because all surfaces in Fig. 2 to Fig. 5 are produced based on the mean values of damping and TSI, the Euclidean Norm is also calculated based on these values. For Cases 2 to 5 , the Euclidean Norm between the surface without DSM and the reference surface and the Euclidean Norm between the surface with DSM and the reference surface are calculated separately at each DSM application hour, the percentage change between these two values is adopted to represent the impacts of DSM.

The Euclidean Norm and corresponding percentage changes of Case 2 to 5 are shown as Fig. 6 to Fig. 9, respectively. Percentage changes of the Euclidean Norm at each DSM application hour are shown on the top of corresponding bars, numbers with upward arrows mean the distance to the reference surface is increased and numbers with downward arrows indicate the distance to the reference surface is decreased. Furthermore, the Euclidean Norm between the surface without DSM and the reference surface is depicted by black solid bars, and the Euclidean Norm between the surface with DSM and the reference surface is depicted by grey patterned bars.

For Case 2 (Fig. 2) and Case 3 (Fig. 3), the white surface is moving towards larger absolute values of damping and TSI, therefore, a larger distance (Euclidean Norm) to the reference

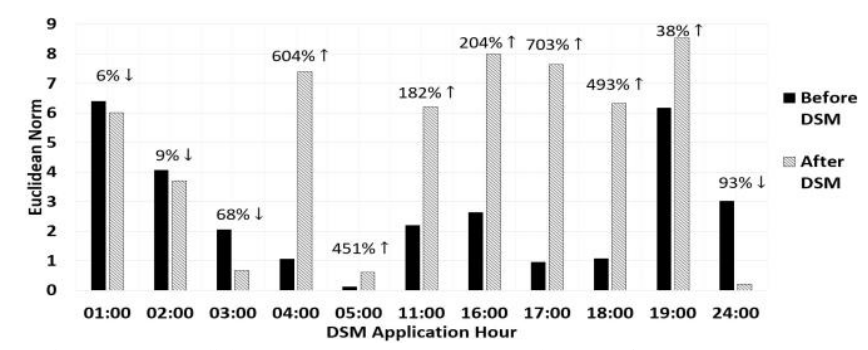

Figure 6. Euclidean Norm and percentage change of Case 2 (50\% RES,

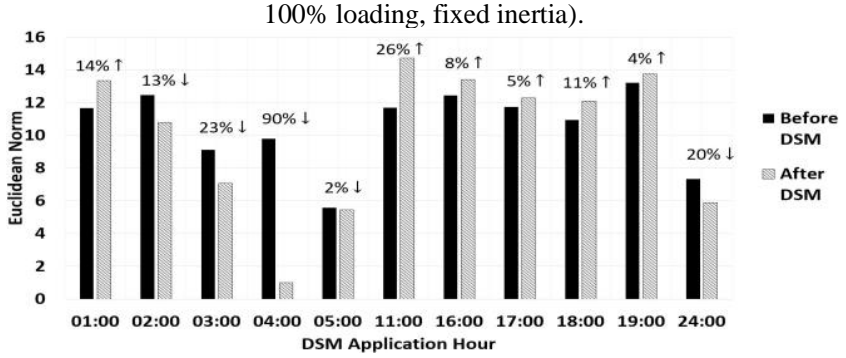

Figure 7. Euclidean Norm and percentage change of Case 3 (50\% RES,

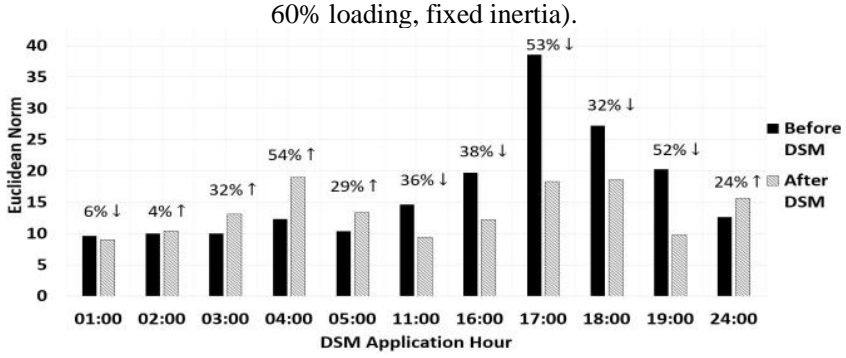

Figure 8. Euclidean Norm and percentage change of Case 4 (30\% RES,

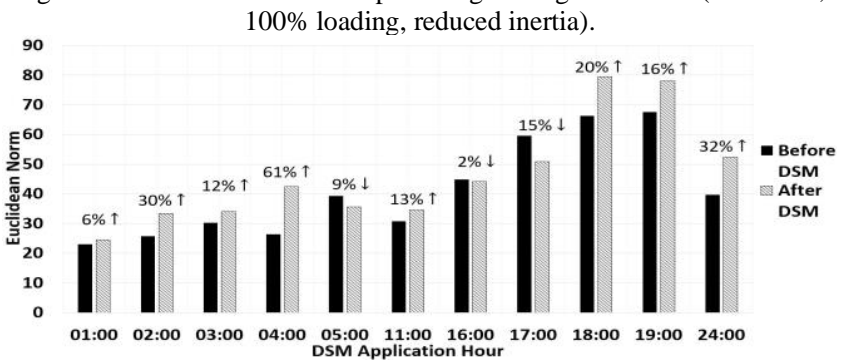

Figure 9. Euclidean Norm and percentage change of Case 5 (60\% RES, $60 \%$ loading, reduced inertia). 
surface should indicate better angular stability performance and a smaller distance to the reference surface should indicate worse angular stability performance. In Fig. 6 and Fig. 7, it can be noticed the Euclidean Norm has increased as a result of the DSM application at load curtailment hours (hours 11, 16, 17, 18 and 19). So, for a system with fixed system inertia, load curtailment can improve system angular stability.

On the other hand, load increases (after reconnection of previously disconnected load) can result in both distance increases and decreases. During the hours when the load is increased due to the reconnection (hours 1, 2, 3, 4, 5 and 24), the distance reduction can be observed at hours 2, 3 and 24 hence system angular stability at these hours becomes worse after applying DSM.

Regarding Cases 4 and 5, based on Fig. 4 and Fig. 5, the white surface in these two cases is shifting towards smaller absolute values of damping and TSI, thus a larger distance (Euclidean Norm) to the reference surface indicates worse angular stability performances while smaller distance indicates better angular stability performances.

For Case 4 (Fig. 8), the Euclidean Norm decreased at all load curtailment hours (hours 11, 16, 17, 18 and 19), and increased at 5 (out of 6) load increased hours. Only at hour 1, an increased load results in a reduction of the Euclidean Norm and better angular stability performance.

In Case 5 (Fig. 9), the Euclidean Norm increased most of the time which indicates worse system angular stability performances. Based on the above discussion, it can be concluded that in this case the TSI changes are driving the overall Euclidean Norm changes. In cases like this therefore, when the opposite effect is observed on different system performance indices, the appropriate weighting factors should be introduced to account appropriately for the effect on the overall system performance.

\section{CONCLUSIONS}

The paper described and illustrated a methodology for assessment of the overall impacts of DSM on power system angular stability. The methodology relies calculating multidimensional surfaces in the system parameter space and assessing the distance between them using Euclidean Norm. The methodology is illustrated using a probabilistic calculation of the test system angular stability over the 24hour period considering system uncertainties coming from generation, load demand and fault profiles for a range of case studies. It has been demonstrated that the connection of RES and system de-loading have different impacts on system angular stability when considering different system inertia levels.

In terms of DSM, the overall effect of DSM on power system angular stability is highly dependent on the system operating conditions. It has been shown that the DSM could either improve or reduce system angular stability (globally or different aspects of it) depending on the system operating condition.

The increases or decreases of distances (Euclidean Norm) between the appropriate multi-dimensional surfaces in the system parameter space (following the adoption of the reference direction) can directly reflect the impacts of DSM or any other control actions on system performance.

\section{ACKNOWLEDGEMENT AND DISCLAIMER}

The research is supported and partially sponsored by the EU H2020 project CROSSBOW (Grant Agreement no. 773430). This paper reflects only the authors' views and neither the Agency nor the Commission are responsible for any use that may be made of the information contained therein. Dr A. Adrees and Dr P. Papadopoulos developed the test network and corresponding loading scenarios adpoted in this study as a part of their research.

\section{REFERENCES}

[1] Y. Dong, X. Xie, K. Wang, B. Zhou and Q. Jiang. "An EmergencyDemand-Response Based Under Speed Load Shedding Scheme to Improve Short-Term Voltage Stability," IEEE Trans. Power Systems, vol. 32, pp. 3726-3735. Sept. 2017.

[2] M. Yao, J. L. Mathieu and D. K. Molzahn. "Using Demand Response to Improve Power System Voltage Stability Margins".

[3] H. W. Qazi and D. Flynn. "Analysing the impact of large-scale decentralized demand side response on frequency stability," ELSEVIER. Electrical Power and Energy Systems 80 (2016) 1-9.

[4] G. Benysek, J. Bojarski, M. Jarnut and R. Smolenski. "Decentralized Active Demand Response (DADR) system for improvement of frequency stability in distribution network," ELSEVIER. Electrical Power Systems Research 134 (2016) 80-87.

[5] J. A. Short, D. G. Infield and L. L. Freris. "Stabilization of Grid Frequency Through Dynamic Demand Control," IEEE Trans. Power Systems, vol. 22, pp. 1284-1293, July 2007.

[6] J. V. Milanovic and I. A. Hiskens, "Effects of load dynamics on power system damping," IEEE Trans. Power Syst., vol. 10, no. 2, pp. 10221028, 1995.

[7] P. N. Papadopoulos, A. Adrees and J. V. Milanovic. "Probabilistic Assessment of Transient Stability in Reduced Inertia Systems," Power and Energy Society Genera Meeting (PESGM), Boston, MA, USA, 2016.

[8] P. Kundur, J. Paserba, V. Ajjarapu, G. Andersson, A. Bose, C. Canizares, N. Hatziargyrious, D. Hill, A. Stankovic, C. Taylor, T. V. Cutsem and V. Vittal. "Definition and classification of power system stability IEEE/CIGRE joint task force on stability terms and definitions," IEEE Trans. Power Systems, vol. 19, pp. 1387-1401, May 2004.

[9] M. Starke, N. Alkadi and O. Ma. "Assessment of Industrial Load for Demand Response across U.S. Regions of the Western Interconnect," ORNL., Oak Ridge, Tennessee, USA. Sept. 2013.

[10] The University of Edinburgh, "Matching Renewable Electricity Generation with Demand," Scottish Executive, Edinburgh, 2006.

[11] National Renewable Energy Laboratory. PVWatts Viewer [Online]. Available: http://gisatnrel.nrel.gov/PVWatters_Viewer/index.html..

[12] S. Tao, Y. Ruoying, Z. Lingzhi and G. Shan, "Power system probabilistic production simulation containing large-scale wind power and photovoltaic power," in Proc. IEEE PES Asia-Pacific Power Energy Eng. Conf., Dec. 8-11, 2013, pp. 1-6.

[13] M. Fan, V. Vittal, G. Heydt and R. Ayyanar, "Probabilistic power flow studies for transmission systems with photovoltaic generation using cumulants," IEEE Trans. Power Systems, vol. 27, no. 4, pp. 2251-2261, Nov. 2012

[14] T. Guo and J. V. Milanovic, "Probabilistic framework for assessing the accuracy of data mining tool for online prediction of transient stability," IEEE Trans. Power Systems, vol. 29, no. 1, pp. 377-385, Jan. 2014.

[15] T. Guo and J. V. Milanovic, "Online identification of power system dynamic signature using PMU measurements and data mining," IEEE Trans. Power Systems, vol. 31, no. 3, pp. 1760-1768, May 2016.

[16] R. D. Zimmerman, C. E. Murillo-Sanchez and R. J. Thomas, "MATPOWER: Steady-state operations, planning and analysis tools for power system research and education," IEEE Trans. Power Systems, vol. 26, no. 1, pp. 12-19, Feb. 2011.

[17] K. N. Hasan, R. Preece and J. V. Milanovic, "Efficient identification of critical parameters affecting the small-disturbance stability of power 


\section{ACCEPTED VERSION OF THE PAPER}

systems with variable uncertainty," Power and Energy Society General Meeting (PESGM), 2016.

[18] A. Almutairi, "Enhancement of Power System Stability Using Wide Area Measurement System Based Damping Controller", Doctor of Philosophy, The University of Manchester, 2010. 